\title{
Structural and Morphological Properties of Nanostructured ZnO Particles Grown by Ultrasonic Spray Pyrolysis Method with Horizontal Furnace
}

\author{
G. Flores-Carrasco, ${ }^{1}$ J. Carrillo-López, ${ }^{1}$ J. A. Luna-López, ${ }^{1}$ R. Martínez-Martínez, ${ }^{2}$ \\ N. D. Espinosa-Torres, ${ }^{1}$ and M. E. Rabanal ${ }^{3}$ \\ ${ }^{1}$ CIDS-ICUAP Benemérita Universidad Autónoma de Puebla, Avenida San Claudio y 14 Sur, Edificio 103C, \\ Ciudad Universitaria, Colonia San Manuel, 72570 Puebla, PUE, Mexico \\ ${ }^{2}$ Instituto de Física y Matemáticas, Universidad Tecnológica de la Mixteca, Carretera a Acatlima Km. 2.5, \\ 69000 Huajuapan de León, OAX, Mexico \\ ${ }^{3}$ Department of Materials Science and Engineering and Chemical Engineering, University Carlos III of Madrid and IAAB, \\ Avenue Universidad 30, Leganes, 28911 Madrid, Spain
}

Correspondence should be addressed to G. Flores-Carrasco; flcagr@hotmail.com

Received 17 April 2014; Accepted 10 June 2014; Published 10 August 2014

Academic Editor: You Song

Copyright (C) 2014 G. Flores-Carrasco et al. This is an open access article distributed under the Creative Commons Attribution License, which permits unrestricted use, distribution, and reproduction in any medium, provided the original work is properly cited.

$\mathrm{ZnO}$ nanoparticles were synthesized in a horizontal furnace at $500^{\circ} \mathrm{C}$ using different zinc nitrate hexahydrate concentrations $(0.01$ and $0.1 \mathrm{M})$ as reactive solution by ultrasonic spray pyrolysis method. The physical-chemical properties of synthesized $\mathrm{ZnO}$ nanoparticles have been characterized by thermogravimetric analysis (TGA), X-ray diffraction (XRD), scanning electron microscopy (SEM), energy dispersive spectroscopy (EDS), and high resolution transmission electron microscopy (HRTEM). With the TGA is has optimized the temperature at which the initial reactive $\left(\mathrm{Zn}\left(\mathrm{NO}_{3}\right)_{2} \cdot 6 \mathrm{H}_{2} \mathrm{O}\right)$, is decomposed completely to give way to its corresponding oxide, $\mathrm{ZnO}$. SEM revealed secondary particles with a quasispherical shape that do not change significantly with the increasing of precursor solution concentration as well as some content of the broken spheres. Increasing the precursor solution concentration leads to the increase in the average size of $\mathrm{ZnO}$ secondary particles from $248 \pm 73$ to $470 \pm 160 \mathrm{~nm}$; XRD reveals the similar tendency for the crystallite size which changes from $23 \pm 4$ to $45 \pm 4 \mathrm{~nm}$. HRTEM implies that the secondary particles are with hierarchical structure composed of primary nanosized subunits. These results showed that the precursor concentration plays an important role in the evolution on the size, stoichiometry, and morphology of $\mathrm{ZnO}$ nanoparticles.

\section{Introduction}

$\mathrm{ZnO}$, which belongs to II-VI group compound semiconductor materials, has been extensively studied in recent years for its many advantages. Due to a direct band gap of $3.37 \mathrm{eV}$ and large exciton binding energy $(\sim 60 \mathrm{meV}), \mathrm{ZnO}$ was used in a wide range of electronic and optical applications such as transparent electrodes [1], light emitting diodes (LEDs) [2], varistors [3], field-effect transistors [4], and solar cell [5]. Also, other advantages of high oxidation ability, high sensitivity for many gases, and low costs were considered in application of gas sensors [6]. Due to the various attractive properties and potential applications of $\mathrm{ZnO}$, there has been much attention paid on the fabrication of $\mathrm{ZnO}$ nanoparticles in recent years.

Up to now, $\mathrm{ZnO}$ particles have been synthesized by various techniques including sol-gel method [7], hydrothermal synthesis method [8], chemical vapor deposition (CVD) [9], precipitation method [10], laser vaporization condensation method [11], and ultrasonic spray pyrolysis (USP) method [12]. Among these techniques, USP process has been successfully applied to synthesize a wide variety of inorganic and organic materials. Unlike physical vapour deposition methods, USP does not require high quality target and nor does it require vacuum at any stage, which is a great advantage if the technique is to be scaled up for the industrial applications. 


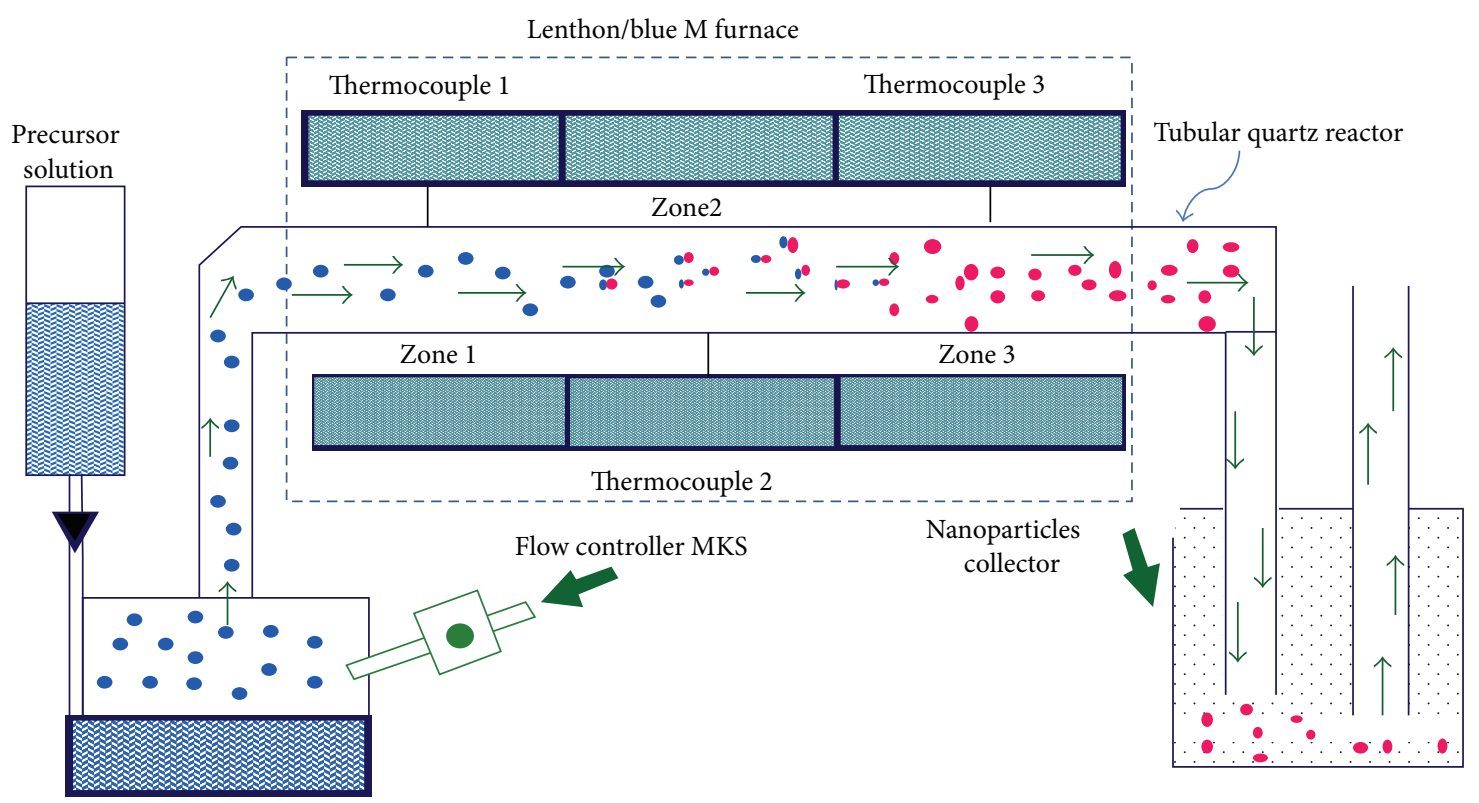

Ultrasonic nebulizer

FIGURE 1: Schematic diagram of the USP system with horizontal furnace.

In general the USP technique has many advantages, like high purity of synthesized particles, regular shape of particles, and a better control of chemical stoichiometry. Also, this technique makes the experimental process relatively simple.

In the present investigation, we have synthesized $\mathrm{ZnO}$ particles at low temperature using the USP technique for having better temperature control and longer residence time particularly in the evaporation/drying stage. In order to provide a better control over the particle morphology processing was done from different precursor solution concentrations $(0.01$ and $0.1 \mathrm{M})$. The influence of experimental conditions on the particle size, morphology, chemical stoichiometry, and crystallinity on the $\mathrm{ZnO}$ nanoparticles was followed, as well.

\section{Experimental Procedure}

2.1. Preparation of Nanostructured $\mathrm{ZnO}$ Particles. $\mathrm{ZnO}$ nanostructured particles were prepared from aqueous solution of zinc nitrate hexahydrate $\left(\mathrm{Zn}\left(\mathrm{NO}_{3}\right)_{2} \cdot 6 \mathrm{H}_{2} \mathrm{O}\right)$ (purity $>99 \%$, Sigma-Aldrich, USA) (0.01 and $0.1 \mathrm{M})$, as the precursor solution. USP is an effective technique for preparation of homogeneous particle compositions in single step. The distribution of particle size produced by USP is narrow and controllable from nanometer to micrometer range, the purity of product is high, and composition of the $\mathrm{ZnO}$ nanoparticles in powder is easy to control. In the present study, $\mathrm{ZnO}$ powder was prepared using the USP process with horizontal furnace, and a schematic diagram of the bench-scale USP system is shown in Figure 1. The USP system setup consists of three zones basically. The first USP zone is to generate the spray from precursor. The precursor solution was placed in bath situated at the upper part of USP equipment (ultrasonic nebulizer RBI with a resonant frequency at $2.1 \mathrm{MHz}$ ). The spray of precursor solution was generated by ultrasonic vibrations, and the resulting droplets were then carrying into system with air carrier gas with flow of 1.5 SLPM (flow controller MKS Model 1179, Andover, MA). The second heating zone, in which the droplets were then carried into tubular quartz reactor $(10.16 \mathrm{~cm}$ in diameter and $156 \mathrm{~cm}$ in length) located in the horizontal furnace of three zones $(108 \mathrm{~cm}$ in length, Lenthon Model Blue M made in England) of high temperature which is maintained at $500^{\circ} \mathrm{C}$ for $2 \mathrm{~h}$. The residence time of the mist particles is about $30-32 \mathrm{~s}$ in zone 3 of the horizontal furnace. The last and third zone is for the trapping of produced powder.

2.2. Estimation of Droplet Diameter. The average diameter of the mist droplet was approximately calculated from an expression given by Lang [13]:

$$
D_{d}=0.34\left(\frac{8 \pi \Upsilon}{\rho f^{2}}\right)^{1 / 3}
$$

where $D_{d}$ is the droplet diameter, $\Upsilon$ is the solution surface tension, $\rho$ is the solution density, and $f$ is the applied ultrasonic frequency. The surface tension of the solution was measured by Quinke's method which was found to be $72.49 \mathrm{dyn} / \mathrm{cm}$. The density was determined by specific gravity bottle which was estimated to be $1.003 \mathrm{~g} / \mathrm{cm}^{3}$. The diameter of the mist droplets in our experiment was calculated using the above expression and was found to be around $2.52 \mu \mathrm{m}$.

2.3. Characterization. The characterization of the as-received precursor was carried out by thermogravimetric analysis (TGA, Perkin-Elmer Model TGA-7) under air flow for removal of product gases. The heating rate was set at $5^{\circ} \mathrm{C} / \mathrm{min}$ from $40^{\circ} \mathrm{C}$ to $1200^{\circ} \mathrm{C}$. The mean particle size and structure of synthesized $\mathrm{ZnO}$ particles were observed by X-ray diffractometer (Philips X'pert) using $\mathrm{CuK} \alpha$ radiation $(\lambda=1.54 \AA$ ) 


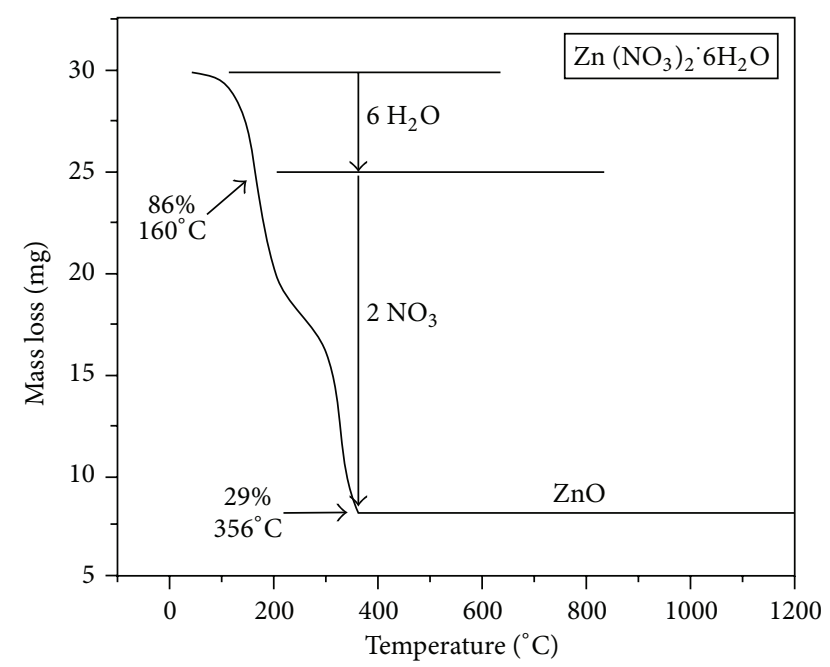

FIGURE 2: Thermogravimetric analysis (TGA) curve of precursor $\mathrm{Zn}\left(\mathrm{NO}_{3}\right)_{2} \cdot 6 \mathrm{H}_{2} \mathrm{O}$.

in the range of $2 \theta$ value between $20^{\circ}$ and $60^{\circ}$. The average crystallite size (CS) by Scherrer formula has been calculated. The equation defined the relation $L=(0.9 \times \lambda) /(B \cos \theta)$, where $L$ is the average crystallite size (in $\AA$ ), $\lambda$ the X-ray wavelength (in $\AA$ ), $B$ the full width half-maximum (FWHM) (in $\mathrm{rad}$ ), and $\theta$ is the diffraction angle the position of the peak (in rad) data used in this calculation [14]. The particle sizes, morphology, and chemical composition were analyzed from scanning electron microscopy (PhilipsXL 30/EDS D×4). High resolution transmission electron microscopy (HRTEM) and X-ray energy dispersive spectroscopy (XEDS) analyses have been carried out to study the morphology, grain size, and chemical composition using a JEOL JEM 2100.

\section{Results and Discussions}

The precursor weight loss by TGA analysis used in the present study is shown in Figure 2. TGA curve shows that the precursor $\left(\mathrm{Zn}\left(\mathrm{NO}_{3}\right)_{2} \cdot 6 \mathrm{H}_{2} \mathrm{O}\right)$ exhibits two different weight loss mechanisms in the temperature ranges of $40-160^{\circ} \mathrm{C}$ and $160-356^{\circ} \mathrm{C}$, respectively. Based on the molecular weights of $\mathrm{Zn}\left(\mathrm{NO}_{3}\right)_{2} \cdot 6 \mathrm{H}_{2} \mathrm{O}$ and its decomposition products, the weight loss during the temperature range of $40-160^{\circ} \mathrm{C}$ can be attributed to water evaporation. Then at range $160-356^{\circ} \mathrm{C}$ the weight loss mechanism may be attributed to nitrates, and the remaining at range $356-1200^{\circ} \mathrm{C}$ is the formation of the chemical compound into $\mathrm{ZnO}$, respectively. From $356^{\circ} \mathrm{C}$ to $1200^{\circ} \mathrm{C}$ shows the analysis TGA weight stability in the product obtained $\mathrm{ZnO}$. Then, the horizontal furnace temperature was so selected after performing TGA analysis of the corresponding precursor in air atmosphere. The selection criterion was to choose the lowest temperature for which the hydrated zinc nitrate was completely decomposed. There was no further weight loss from 450 to $500^{\circ} \mathrm{C}$. Choosing the lower temperature implies a lower secondary particle growth and therefore having a smaller size in the crystallite size. Therefore this is the chief reason why the USP furnace has not been programmed to higher temperatures.

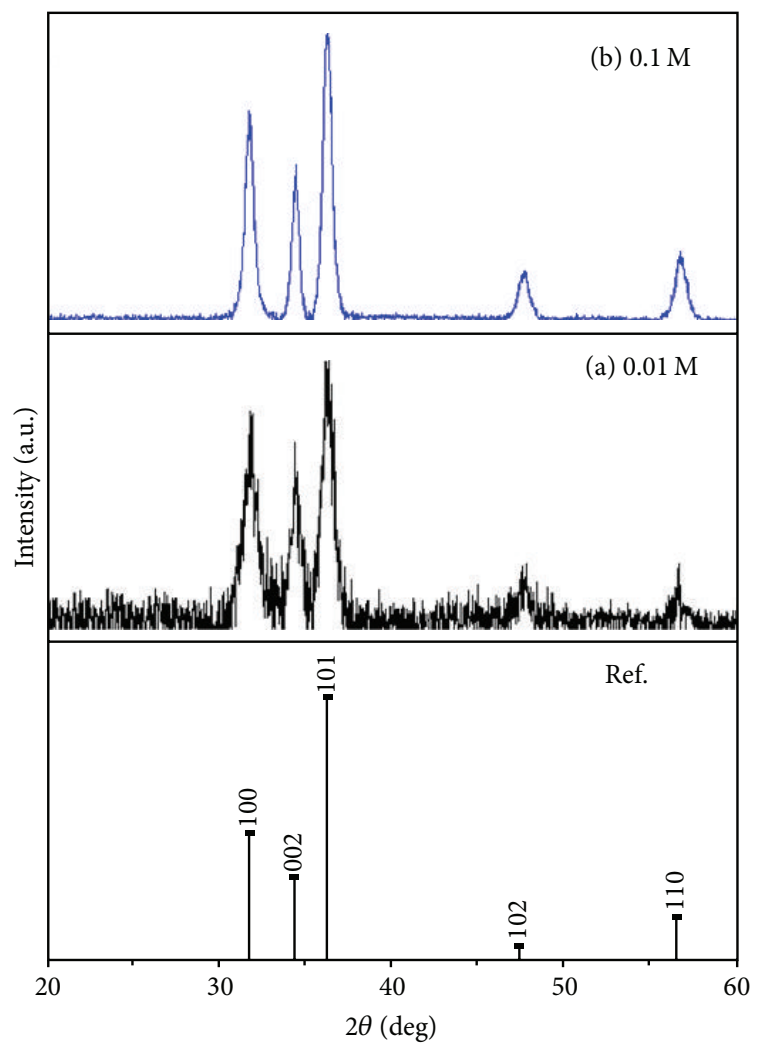

FIGURE 3: XRD patterns of $\mathrm{ZnO}$ nanoparticles at various precursor concentrations. (a) $0.01 \mathrm{M}$ and (b) $0.1 \mathrm{M}$.

So as to confirm the crystalline structure and present phases of synthesized $\mathrm{ZnO}$ powder, the XRD (X-ray diffraction) analysis was carried out. Figure 3 shows XRD patterns for all samples synthesized by USP for $2 \mathrm{~h}$ at $500^{\circ} \mathrm{C}$ from different concentrations of precursor solution of (a) $0.01 \mathrm{M}$ and (b) $0.1 \mathrm{M}$. The powder XRD data for the as-prepared samples reveals a wurtzite structure and the products were more or less crystallized with all X-ray peaks matching with the standard JCPDS file [15]. The crystallite phase of $\mathrm{ZnO}$ matches with PDF: 80-0075 with a space group P63mc of dihexagonal pyramidal class. There were no additional diffraction peaks in the sample. It has been observed, moreover, that the full width at half maximum (FWHM) of the peaks became smaller with an increase of precursor solution concentration. The differences in the characteristic peak intensities and widths with the concentration could be associated with the lower crystallite size of $\mathrm{ZnO}$ particles. The XRD patterns have been used to calculate the crystallite size of the $\mathrm{ZnO}$ nanoparticles using Scherrer's formula. The crystallite size is shown in Table 1 . It was found that the crystallite size of $\mathrm{ZnO}$ nanoparticles is $\sim 23 \pm 4 \mathrm{~nm}$ to $0.01 \mathrm{M}$ which increased to $\sim 45 \pm 4 \mathrm{~nm}$ when the precursor solution concentration is $0.1 \mathrm{M}$. This estimation confirms the observations seen from the XRD patterns.

Typical morphology of $\mathrm{ZnO}$ nanoparticles obtained by USP at low and high magnification is shown. In Figures 4(a)-4(d) quasispherical shape, nonagglomerated particles are visible in $\mathrm{ZnO}$ powder samples. In the case of $0.01 \mathrm{M}$ 


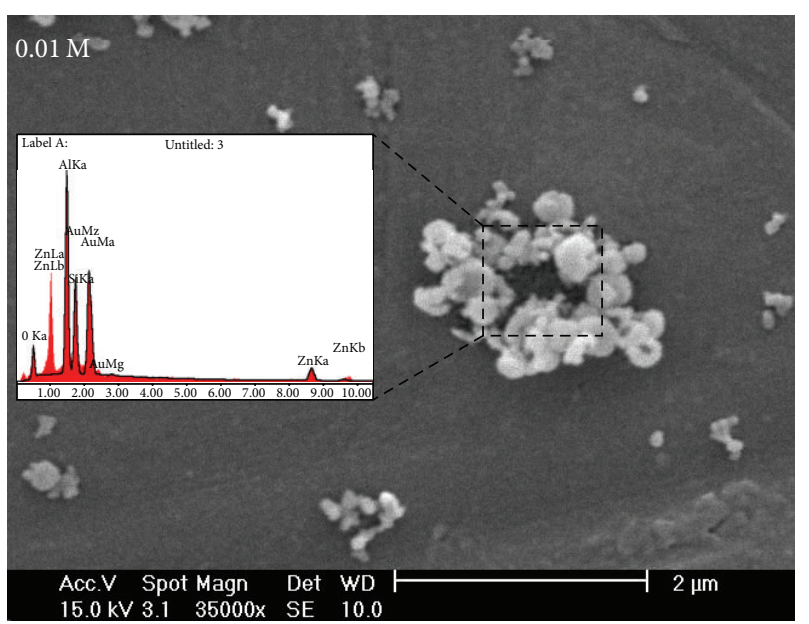

(a)

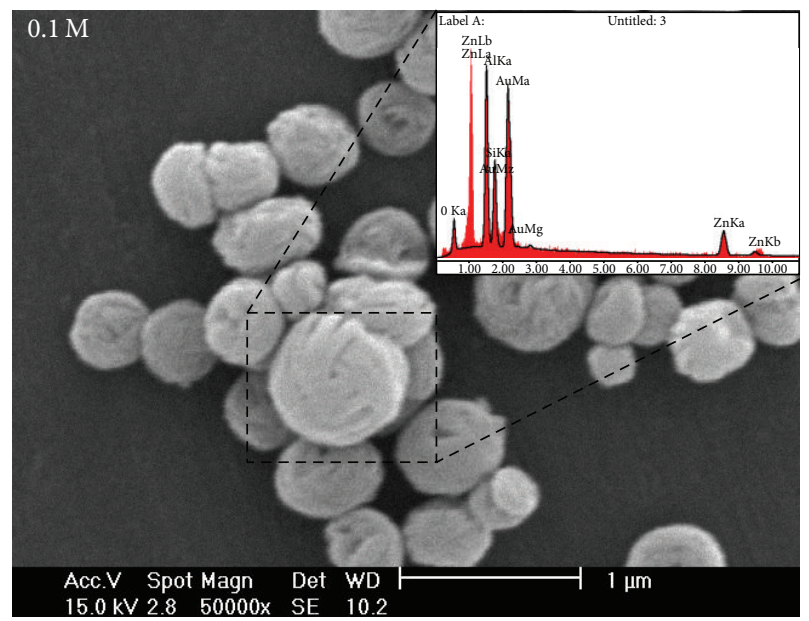

(c)

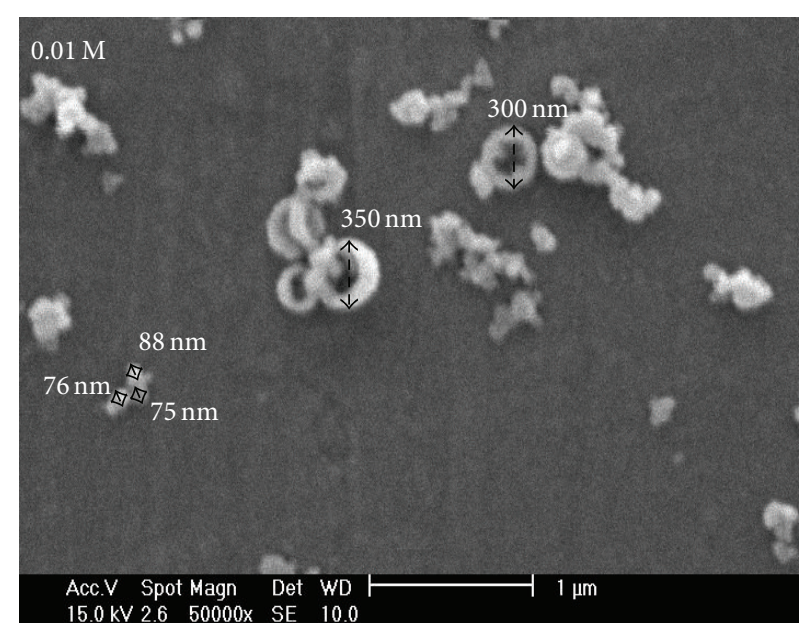

(b)

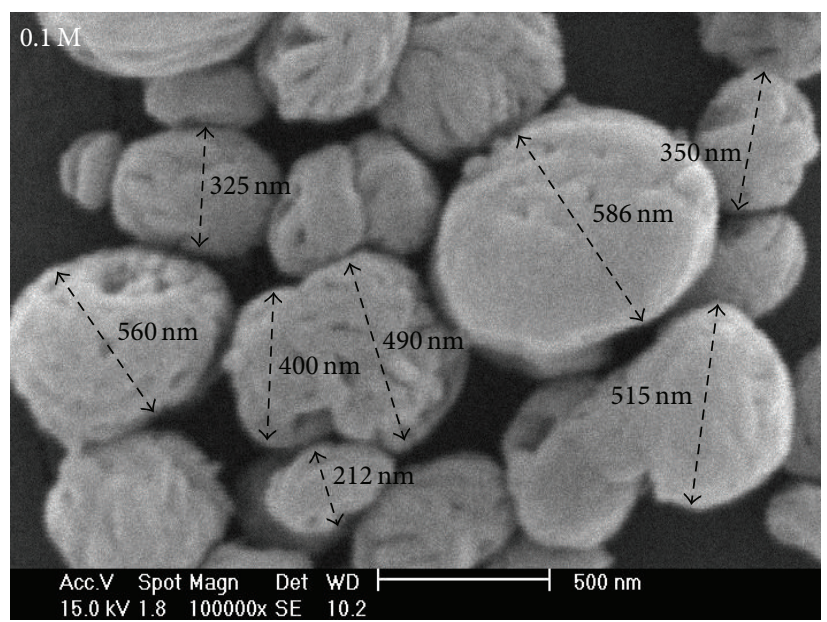

(d)

FIGURE 4: Low and high of magnification scanning electron micrographs of $\mathrm{ZnO}$ nanoparticles synthesized from the precursor solution of $0.01 \mathrm{M}((\mathrm{a})-(\mathrm{b}))$ and $0.1 \mathrm{M}((\mathrm{c})-(\mathrm{d}))$.

TABLE 1: Variation of crystallite size considering the three most intense diffraction peaks of synthesized $\mathrm{ZnO}$ nanoparticles at precursor concentration of 0.01 and $0.1 \mathrm{M}$, respectively.

\begin{tabular}{lcccc}
\hline $\begin{array}{l}\text { Precursor solution } \\
\text { concentration }\end{array}$ & 100 & 002 & 101 & $\begin{array}{c}\text { Crystallite size } \\
(\mathrm{nm})\end{array}$ \\
\hline $0.01 \mathrm{M}$ & $31.753^{\circ}$ & $34.443^{\circ}$ & $36.264^{\circ}$ & $23 \pm 4$ \\
$0.1 \mathrm{M}$ & $31.747^{\circ}$ & $34.349^{\circ}$ & $36.257^{\circ}$ & $45 \pm 4$ \\
\hline
\end{tabular}

concentration (Figures 4(a) and 4(b)), the secondary particle size $(\sim 248 \pm 73 \mathrm{~nm})$ is the lowest and is possible to distinguish hollow particles. Formation of more uniform and dense secondary particles can be observed when higher concentration has been used. As we can see in the micrographs (Figures 4(c) and 4(d)), formation of secondary particles with average size of around $\sim 470 \pm 160 \mathrm{~nm}$ to $0.1 \mathrm{M}$ of precursor solution concentration is found. In the case of USP, hollow, porous, or crushed structure particles can be formed when a solute concentration gradient is created during evaporation of the droplet. The solute precipitates first on the more highly supersaturated surface if the sufficient time is not available for solute diffusion in the droplet (the solvent (e.g., water) evaporation characteristic time is shorter than the solute diffusion characteristic time). However, for the droplet sizes used in these experiments (of about $2.52 \mu \mathrm{m}$ for ultrasound frequency of $2.1 \mathrm{MHz}$ ), the temperature distribution along the radius of a droplet could be presumably ignored because of small Biot number [16]. If so, the resistance to heat flow within the solid is small relative to the resistance presented by the convection processes at the surface causing the temperature uniformity inside the droplet and at the droplet surface. This implicates that either hollow or solid particle formation is likely caused by the percolation criterion implying that the solution concentration is an important factor to influence the particle morphology. Denser and bigger particles are observed when higher precursor solution concentrations have been used. Insets in Figures 4(a) and 4(c) present the EDS spectra of $\mathrm{ZnO}$ particles analyzed. These spectra show that the composition of nanostructured particles mainly 


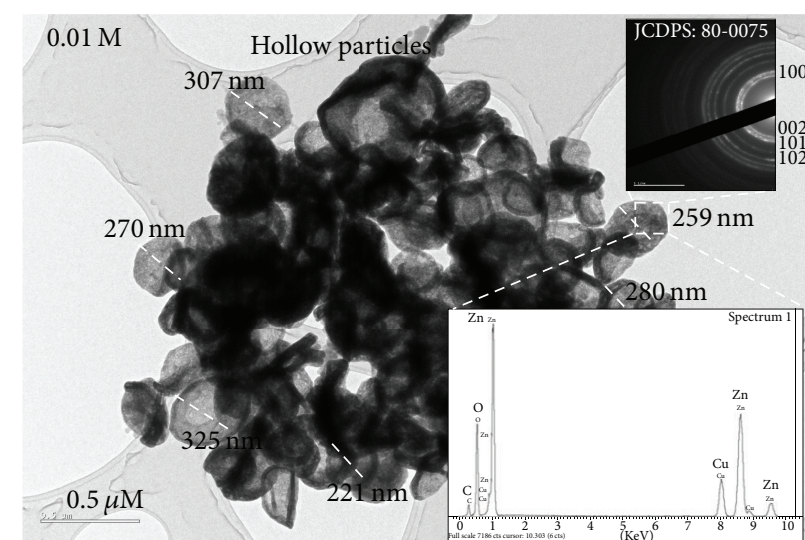

(a)

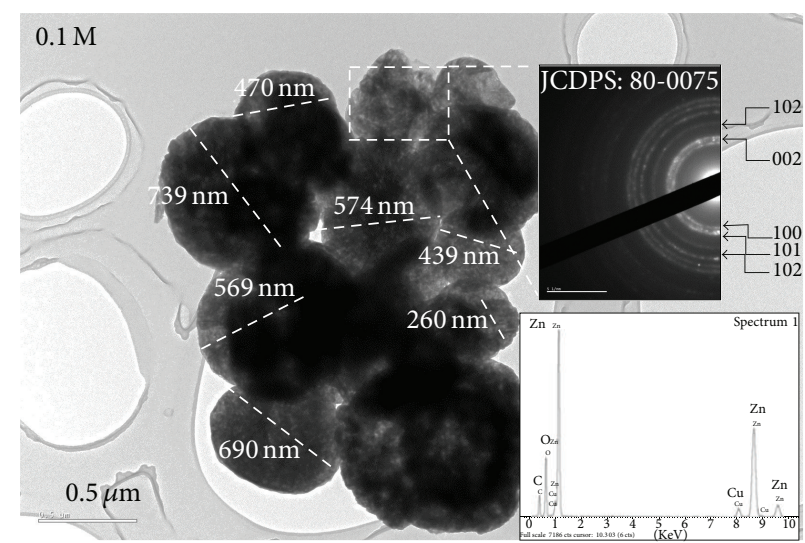

(b)

FIGURE 5: TEM and HRTEM micrographs of ZnO nanoparticles synthesized at various precursor concentrations. (a) $0.01 \mathrm{M}$ showing hollow and quasi-spherical particles and (b) $0.1 \mathrm{M}$ showing dense, quasispherical, and bigger particles.

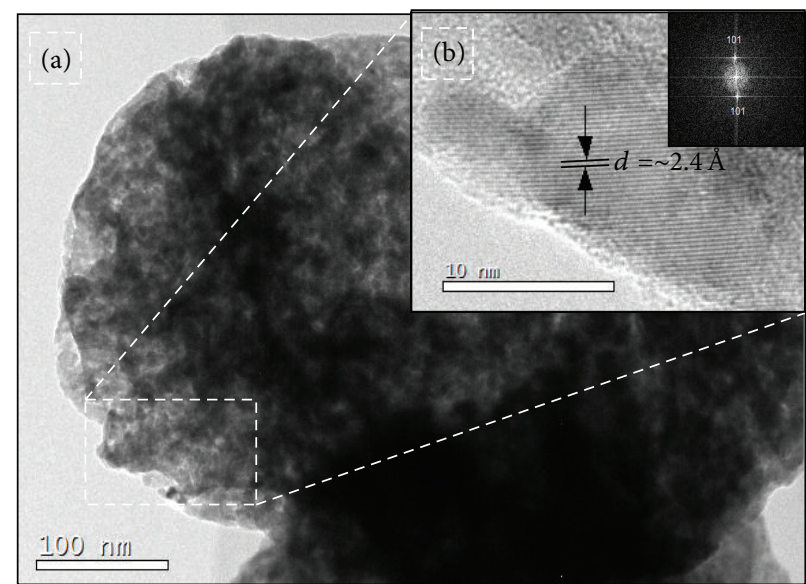

FIGURE 6: TEM and HRTEM images of ZnO nanoparticles synthesized from precursor solution concentration of (a) $0.1 \mathrm{M}$ and (b) the inset is the corresponding FFT pattern of HRTEM image.

consist of $\mathrm{Zn}$ and $\mathrm{O}$ with a negligible presence of $\mathrm{Si}$, and the $\mathrm{Zn}$ content of the two samples is about 50.63 and $61.79 \%$. This area energy dispersive X-ray analysis (EDAX) has confirmed excellent homogeneity of the samples and is in good agreement with the nominal starting composition. The negligible presence of $\mathrm{Si}$ could be due to quartz tube used in the USP equipment and $\mathrm{Al}$ is the material of measurement crucibles.

The morphology and microstructure of the $\mathrm{ZnO}$ particles have further been analyzed by TEM and HRTEM. Figures 5(a)-5(b) show the TEM micrograph of the $\mathrm{ZnO}$ nanoparticles obtained from 0.01 and $0.1 \mathrm{M}$ concentrations. In Figure 5(a) TEM micrograph of the $\mathrm{ZnO}$ particles synthesized clearly revealed quasispherical and hollow particles with a good distribution of secondary particle size. The average diameter of the quasispherical particles varied from $\sim 180$ to $\sim 360 \mathrm{~nm}$. The size of the secondary particles agrees with SEM analysis. Furthermore, the diffraction rings, as the characteristic of polycrystalline particles, correspond to crystallographic orientations of (100), (002), (101), and (102) in a hexagonal wurtzite structure. The chemical composition of a selected area confirms the presence of $\mathrm{ZnO}$ nanostructured particles and a small amount of $\mathrm{Si}$ comes from quartz tube. Figure 5(b) shows TEM images of $\mathrm{ZnO}$ particles obtained from $0.1 \mathrm{M}$ precursor solution. As can be seen, most of the particles are denser than the nanostructures obtained from a concentration of $0.01 \mathrm{M}$, with an average diameter from $\sim 400$ to $\sim 740 \mathrm{~nm}$ when a precursor concentration of $0.1 \mathrm{M}$ has been used. In both micrographs (see Figures 5(a) and $5(\mathrm{~b})$ ), the inset of EDS confirms the polycrystalline nature of the samples, and EDAX spectrum reinforces the chemical composition of particles as pure $\mathrm{ZnO}$. Figures 6(a) and 6(b) show the TEM and HRTEM images for the $\mathrm{ZnO}$ nanoparticles with higher precursor concentration. The corresponding region of HRTEM image clearly shows parallel crystal planes indicating that the nanostructures are highly crystallized, in concordance with the XRD analysis. The particles obtained from $0.1 \mathrm{M}$ precursor solution exhibit the lattice spacing between the adjacent planes of $\sim 0.24 \mathrm{~nm}$, which matches well the (101) crystal planes of wurtzite $\mathrm{ZnO}$. The fast Fourier transform (FFT) patterns of the HRTEM image are also shown in the figures and are in agreement with the HRTEM results. 


\section{Conclusions}

We obtained successfully synthesized $\mathrm{ZnO}$ nanoparticles by USP method with horizontal furnace under different precursor concentration. All of the samples have the wurtzite hexagonal structure and their mean particle sizes and crystallinity were gradually improved due to higher concentration used in precursor solution. Besides, sizes of the primary and secondary particles in TEM and SEM image tend to increase. HRTEM implies that the secondary particles are with hierarchical structure composed of primary nanosized subunits. In summary, a very simple and low-cost route has been developed to prepare nanostructured $\mathrm{ZnO}$ particles with different size, chemical stoichiometry, and morphology.

\section{Conflict of Interests}

The authors declare that there is no conflict of interests regarding the publication of this paper.

\section{Acknowledgments}

This work has been supported by scholarship CONACyT, VIEP-BUAP-2014, S2009/MAT-1585, and MAT2010-19837C06-05. It has been carried out in the Department of Materials Science and Engineering and Chemical Engineering of the University Carlos III of Madrid, Spain.

\section{References}

[1] F. Michelotti, A. Belardini, A. Rousseau, A. Ratsimihety, G. Schoer, and J. Mueller, "Use of sandwich structures with $\mathrm{ZnO}: \mathrm{Al}$ transparent electrodes for the measurement of the electro-optic properties of standard and fluorinated poled copolymers at $\lambda=$ $1.55 \mu \mathrm{m}$," Journal of Non-Crystalline Solids, vol. 352, no. 23-25, pp. 2339-2342, 2006.

[2] H. Guo, J. Zhou, and Z. Lin, "ZnO nanorod light-emitting diodes fabricated by electrochemical approaches," Electrochemistry Communications, vol. 10, no. 1, pp. 146-150, 2008.

[3] M.-H. Wang, C. Yao, and N.-F. Zhang, "Degradation characteristics of low-voltage $\mathrm{ZnO}$ varistor manufactured by chemical coprecipitation processing," Journal of Materials Processing Technology, vol. 202, no. 1-3, pp. 406-411, 2008.

[4] S.-Y. Lee, A. Umar, D. Suh, J.-E. Park, Y.-B. Hahn, and J.-Y. Ahn, "The synthesis of $\mathrm{ZnO}$ nanowires and their subsequent use in high-current field-effect transistors formed by dielectrophoresis alignment," Physica E, vol. 40, no. 4, pp. 866-872, 2008.

[5] A. Belaidi, T. Dittrich, D. Kieven et al., " $\mathrm{ZnO}$-nanorod arrays for solar cells with extremely thin sulfidic absorber," Solar Energy Materials and Solar Cells, vol. 93, no. 6-7, pp. 1033-1036, 2009.

[6] H. Xu, X. Liu, D. Cui, M. Li, and M. Jiang, "A novel method for improving the performance of $\mathrm{ZnO}$ gas sensors," Sensors and Actuators B: Chemical, vol. 114, no. 1, pp. 301-307, 2006.

[7] M. Ristic, S. Music, M. Ivanda, and S. Popovic, "Sol-gel synthesis and characterization of nanocrystalline $\mathrm{ZnO}$ powders," Journal of Alloys and Compounds, vol. 397, no. 1-2, pp. L1-L4, 2005.

[8] K. Sue, K. Kimura, and K. Arai, "Hydrothermal synthesis of $\mathrm{ZnO}$ nanocrystals using microreactor," Materials Letters, vol. 58, no. 25, pp. 3229-3231, 2004.
[9] P. Singh, A. Kumar, and D. Kaur, "ZnO nanocrystalline powder synthesized by ultrasonic mist-chemical vapour deposition," Optical Materials, vol. 30, no. 8, pp. 1316-1322, 2008.

[10] C. Chen, P. Liu, and C. Lu, "Synthesis and characterization of nano-sized $\mathrm{ZnO}$ powders by direct precipitation method," Chemical Engineering Journal, vol. 144, no. 3, pp. 509-513, 2008.

[11] M. S. El-Shall, D. Graiver, U. Pernisz, and M. I. Baraton, "Synthesis and characterization of nanoscale zinc oxide particles: I. laser vaporization/condensation technique," Nanostructured Materials, vol. 6, no. 1-4, pp. 297-300, 1995.

[12] O. Milosevic, V. Gagic, J. Vodnik et al., "Synthesis and deposition of $\mathrm{ZnO}$ based particles by aerosol spray pyrolysis," Thin Solid Films, vol. 296, no. 1-2, pp. 44-48, 1997.

[13] R. J. Lang, "Ultrasonic atomization of liquids," Journal of the Acoustical Society of America, vol. 34, no. 1, p. 6, 1962.

[14] M. Martín-Gil, M. E. Rabanal, A. Várez, A. Kuhn, and F. GarcíaAlvarado, "Mechanical grinding of $\mathrm{Si}_{3} \mathrm{~N}_{4}$ to be used as an electrode in lithium batteries," Materials Letters, vol. 57, no. 20, pp. 3063-3069, 2003.

[15] Joint Committee on Powder Diffraction Standard, "JCPDS International Center for Diffraction Data, Pennsylvania," 1991.

[16] I. Dugandžić, V. Lojpur, L. Mančić et al., "Aerosol route as a feasible bottom-up chemical approach for up-converting phosphor particles processing," Advanced Powder Technology, vol. 24, no. 5, pp. 852-857, 2013. 

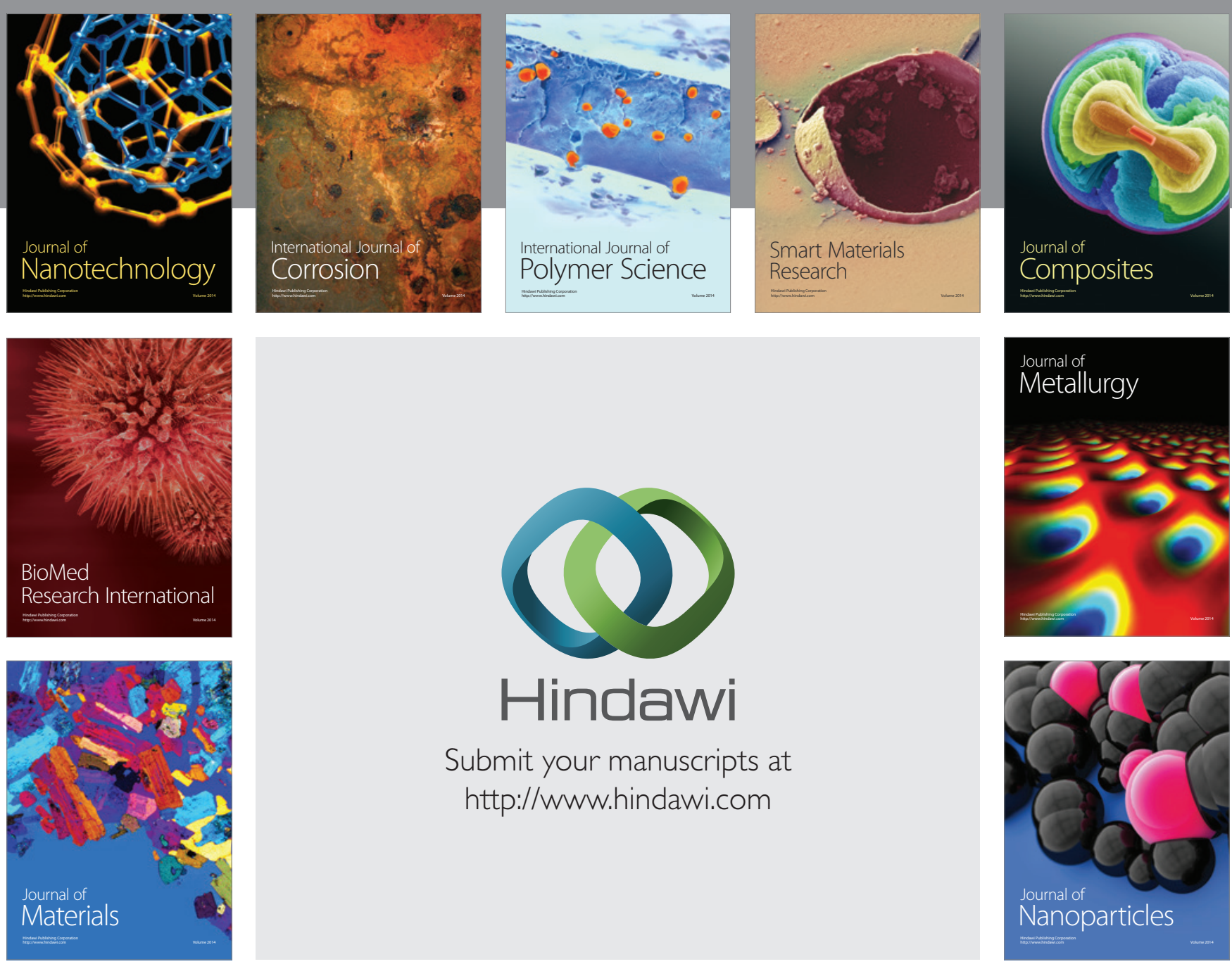

Submit your manuscripts at http://www.hindawi.com
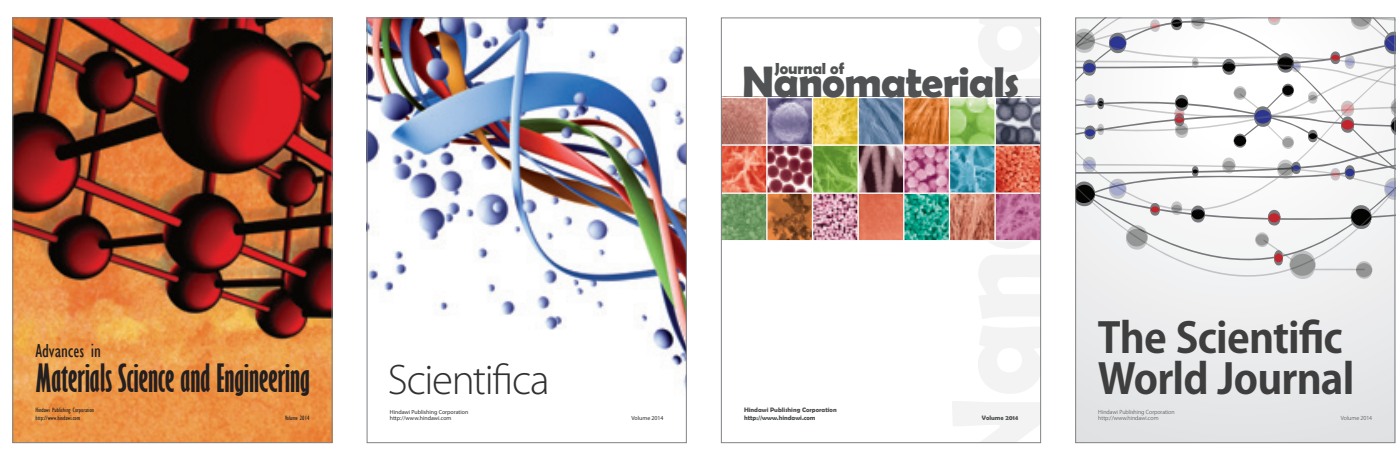

\section{The Scientific World Journal}
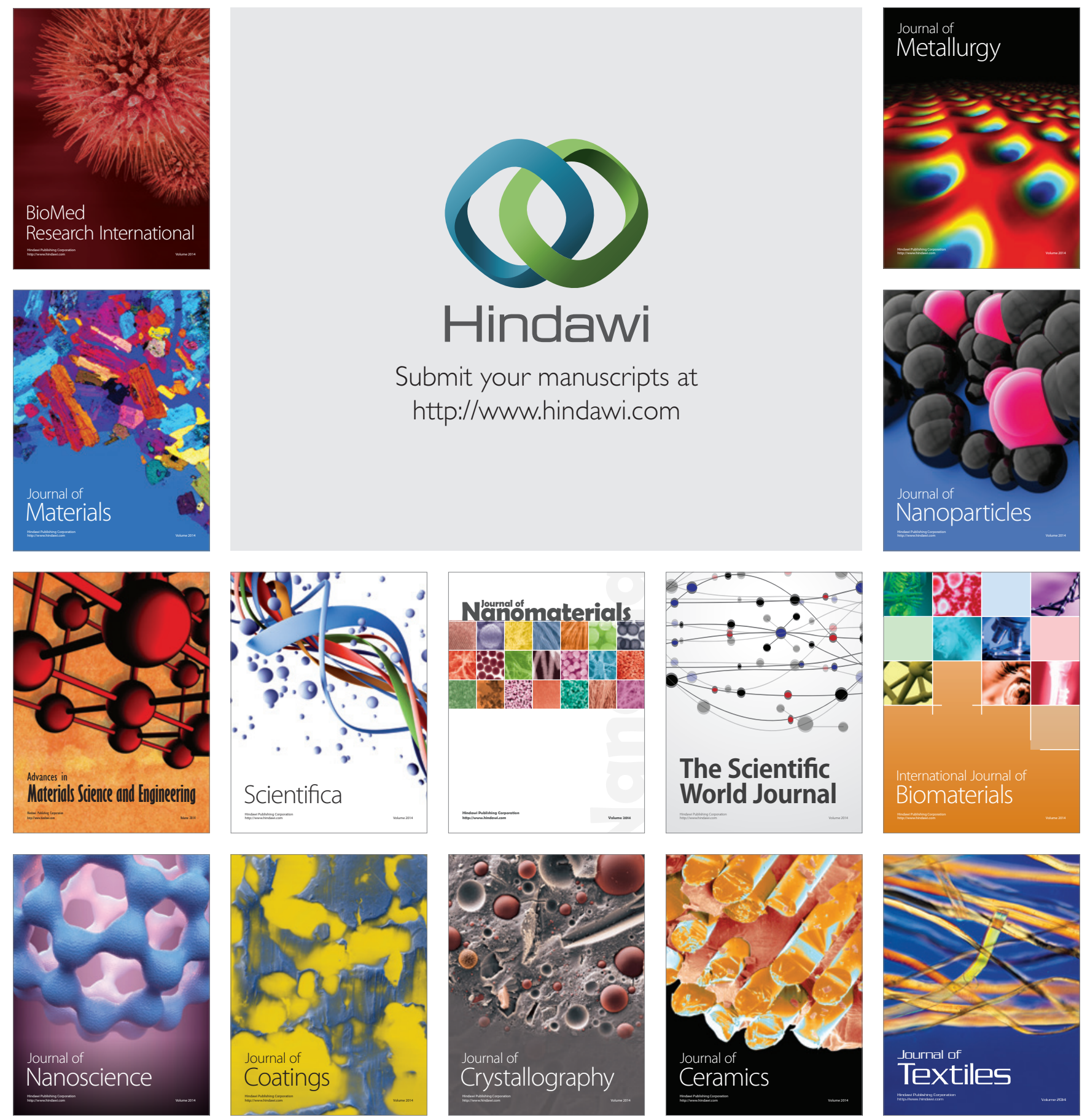